\title{
Research on Inheritance and Protection of Intangible Cultural Heritage in Dazhou City — Taking the Folk Songs of Madu Township as an Example
}

\begin{abstract}
Gaoyang Liu, ${ }^{1, *}$
${ }^{1}$ Sichuan University of Arts and Science, Dazhou, Sichuan 635000, China

*Corresponding author. Email: 1693725957@qq.com

ABSTRACT

In the new era, as China continues to attach importance to "intangible cultural heritage", the academic circles have made researches on the native intangible cultural heritage of Dazhou City. For example, the "weeding gongs and drums" of Tujia nationality in Chuandong, and the "Zhu Suona" of Dazhu County, "Pan'ge" of Kaijiang, "fire dragon dance" of Shiqiao, and "Fanshan Jiaozi" in Dachuan District have all been studied in detail. However, there are few researches on the folk songs of Madu Township, which was listed as intangible cultural heritage of Sichuan Province in 2018 as an art treasure in Eastern Sichuan. This paper summarizes the status quo of intangible cultural heritage in Dazhou City. And it takes Bashan folk songs as an example to deeply analyze the origins, characteristics of lyrics, modes and tunes, presentation forms, and other ideological connotations. Finally, some suggestions for inheritance and protection are put forwarded combining with the actual situation of Dazhou City.
\end{abstract}

Keywords: intangible cultural heritage, folk songs of Madu Township, inheritance and protection

\section{INTRODUCTION}

The folk songs of Madu Township are originated in Madu Township of Xuanhan County, and are typical representatives of folk songs in eastern Sichuan. It is an important traditional music culture with great influence in Northeast Sichuan because of its large number, changeable styles, rich contents and various forms. Among the 300 songs counted, there are songs about love, songs praising life, folk songs describing production and labor, folk songs recording seasons and rituals, and red songs praising revolution. Its unique creative techniques, beautiful melody, unique lyrics, local customs, historical landforms and humanistic spirit can never be copied. With the reform and opening up and the globalization, China's economy, information and culture have been affected in varying degrees, among which the traditional culture is greatly impacted by western culture. As a traditional music culture, folk songs of Madu Township have gradually faded out of people's sight. There are fewer and fewer inheritors of folk songs, and the singing degree is also becoming lower and lower, which makes folk songs of Madu Township fall into a dangerous situation that is about to

*Fund: This paper is supported by the research results of the project of Dazhou Social Science- "Research on Inheritance and Protection of Intangible Cultural Heritage in Dazhou City - Taking the folk songs of Madu Township as an Example". be lost. In this context, it is of great significance to study the local music culture, as well as the cultural construction and regional economic development of Dazhou City from the perspective of protection and inheritance of folk songs of Madu Township.

\section{INTANGIBLE CULTURAL HERITAGE OF DAZHOU CITY}

Dazhou City is in the east of Sichuan Province, and at the junction of Sichuan Province, Chongqing, Hubei Province and Shaanxi Province. It is a famous old revolutionary base area with abundant products and rich resources. It has a long history and rich cultural heritage. Since the establishment of the county in the Eastern Han Dynasty, it has a history of more than 1900 years. Today, it enjoys the reputation of China's Ramie City, China's Day Lily City, China's Olive City, China's Se-enriched Tea City, and China's County of Toon.

In the long historical process and evolution, it has also gathered rich intangible cultural heritage. According to statistics, Dazhou City has 248 items of intangible cultural heritage to be protected, including 3 items of national intangible cultural heritage, 29 items of provincial intangible cultural heritage, 45 items of municipal intangible cultural heritage and 117 items of county-level intangible cultural heritage. [4] These intangible cultural heritages can be divided into seven 
categories according to their contents. The first is folk literature, such as Wang Yaogongye series of stories, the Spring Festival of Shui nationality and Baqu nursery rhymes; the second is folk music, such as Beierge of Bashan, Kaijiang Pan'ge, Zhu Suona and stonework horn; the third is traditional dance, such as benghe dance, Fanshan Jiaozi, Anrentan's son-grandpa dragon; and the fourth is quyi, such as qiangun, weeding gongs and drums of Tujia nationality in eastern Sichuan; the fifth is traditional sports and acrobatics, such as yumenquan of $\mathrm{Tu}$ nationality, entertainment, and aobang; the sixth is traditional handicrafts, such as Liu's bamboo weaving in Quxian County, traditional processing technology of translucent beef slices in Daxian County, xiajiu brewing technology in Quxian County, laozao brewing technology in Dongliu, and bean production technology in Kaijiang; and the seventh is folk arts, such as shaohuolong in Shiqiao, Sanhui Caitinghui, Dazhou hiking [5].

In 2018, three items, "Madu folk songs", "detumescence drug: snake being hard to climb" and "playing with fire dragon in Gantang", were selected into the fifth batch of provincial intangible cultural heritage, further enriching the culture of intangible cultural heritage in Dazhou City. Among them, "Madu folk song" as the first item of intangible cultural heritage is highly valued and praised by experts and judges.

\section{FOLK SONGS OF MADU TOWNSHIP}

The folk songs of Madu Township are important cultural resources of Dazhou and even Sichuan, and have the reputation of "king of folk songs". There are 400 folk songs in East Sichuan, and more than 200 songs are from Madu Township. Among them, "Su Erjie", "Kangding Love Song", "Bei Er'ge", "Hero crossing the Dadu River", "Looking forward to the Red Army", "longterm-hired song", "leek song", "ten fans", "following the revolution", "pinching moss", "haoer", "welcome to Madu", "musical dialogue", "singing a folk song to the party", "singing for the carrier", "singing for the boatman", "little sister standing on the opposite rock", "love song", "stone song", "Bashan people's happy life", etc. Madu has also been awarded as the hometown of Chinese folk culture and art, the hometown of Sichuan folk art culture and the hometown of Eastern Sichuan folk songs. It is the hometown of $\mathrm{Li}$ yiruo, the author of "Kangding Love Song", one of the "top ten folk songs in the world", and the birthplace of "Su Erjie", one of the four major Chinese folk songs.

\section{A. The unique musicality of Madu folk songs}

Madu folk songs mainly have four lines of lyrics, with seven characters in the majority. There are also five-character sentences, ten-character sentences and mixed sentences. Occasionally, two and a half sentences and five sentences are also used. At the same time, "metaphor", "contrast", "personification", "repetition", "exaggeration" and other techniques and idioms are used to make the lyrics distinctive. There are lyrics describing the production and labor (such as, the sun shines on the Qujiang River, the beautiful scenery on both sides, the boatman is dedicated to the four modernizations, and transportation is busy day and night.); there are lyrics singing love (such as, the snow is blowing in October, people are eager to have a look, and they look to the winter and December.); there are lyrics reflecting daily life (such as, a sister goes to buy a black face, tidies up and goes to see a play.); and there are also lyrics on customs, stories and legends, rituals and revolutionary song [6]. And the padding syllable ( 嗬, 烸, 嘿, 咳, 哼, 哈, 啰, 咧, 啦, 呐, 哇, 吔, 呀, 呃, 咗, 呢) is colorful and vivid.

The melody is beautiful and easy to sing. There is often five-tone mode of Gong, Shang, Jiao, Zheng, and $\mathrm{Yu}$ (do, re, mi, sol, la), as well as the four-tone mode of Gong, Shang, Zheng and $\mathrm{Yu}$, as well as the mode of Gong, Shang, Jiao, Zheng, Yu and partial tone. However, on the whole, it is mainly composed of five tones, and most of them are in mode of Shang and Zheng. For example, songs such as "all life", "going up the hillside", "going to the market", "following the Communist Party all life" are in the mode of Shang; songs such as "short-life love song", "long time not singing and forgeting song", "sister going out to bear the burden" are all in the mode of Zheng. Glide is also a feature of the melody of Madu folk song. In many songs, the glide is added at the end of the paragraph and even in the middle of the sentence. It can not only beautify the music melody, but also make the music vivid and depict the features of the scenery. Adding glide in the melody of songs is mainly due to life and work, and is also affected by regional environment and historical heritage. This not only accords with the heroic and enthusiastic personality of Bashan people, but also reflects the beautiful scenery of Bashan.

The rhythm is free and changeable, rich and colorful. There are three consecutive-tone in some songs, such as "Red Army passing my home", "picking lotus", "Going to the mountain"; there are some free tones in the songs, such as "morning", "pastoral song", "water playing"; there are songs with rhythm, such as "singing for boatman", "singing for the carrier", "boating"; there are songs with weak rhythm, such as "looking forward the coming of man", "sisters and brothers say together", "what comes out high"; and there are songs with syncopated rhythm, such as "walking with the moon", "happy people in Bashan", and "following the Communist Party". There are also a variety of rhythms, such as changing rhythm, 
compound rhythm, ragtime and so on, making the songs flexible and expressive.

\section{B. Rich ideological connotation of Madu folk songs}

Madu folk song has rich and colorful lyrics, beautiful melody, nationalized mode and vivid rhythm. Its creation and singing are the portrayal of people's daily life, and also the true expression of people's aspirations and feelings with songs. It can be summed up as follows:

One is to dare to criticize the old society. Bashan people are hardworking and brave, enthusiastic and heroic. They are also brave in their daily life and work. Whether in labor or leisure time, they like to express their feelings by singing, such as their dissatisfication with the heavy work of the old society and hard life. For example, in the song of "for long-term workers", "on the first day of the first month, there is nothing in the poor people's homes; the pot is hung up and used as bell, people carry the bag and become long-term workers." In "women's bitter love", "women are suffering a lot. They have been tortured since they were born. It's really hard to say anything." In "song of the long years", "on the first day of the first month, the long-term worker washes the clothes. It's sad to leave the old parents and young wife." These songs express people's criticism of the old social life.

Second is to have the spirit of red revolution. Many Madu folk songs express the spirit of red revolution. For example, in "following the Red Army to make a revolution", in "it is raining in front of the mountain, but it is sunny on back of the mountain, the Communist Party is expected to come. A big flag is red, and the local people fight against tyrants and obtain fields. A red flag floats in the air. I make a revolution with the Red Army." In "women's turning over", "men and women are the same and follow the Communist Party, women seek liberation". In "looking forward to the Red Army", "the sun sets, the mountains are in the sunshine, the rhinoceros is looking the moon and women are looking the man. I remember that when chrysanthemum is yellow, I sent the Red Army to Liangshan. I expected the Red Army to turn around early and remember the people's difficulty in the heart." In "revolution depends on the common people", "who makes a revolution? what depends on the common people? the Red Army started a revolution, and the revolution depends on the common people." The Fourth Front Red Army sowed the seeds of revolution here. The Red Army have made effective things for people, such as fighting against local tyrants, dividing fields, saving the poor, and punishing tyrants. People have deep feelings for the Red Army. They look forward to the Red Army, praise the Red Army, send the Red Army and become the Red Army. The spirit of the red revolution is everywhere [7].
The third is to praise the beautiful love and happy life. Madu folk songs not only comment on the past, but also praise the present beautiful life and sweet love. For example, in "a flower", "the flower is red and given to my sister as a headdress, my sister is not afraid of my brother's lies, so I'll give it to you tomorrow". In "the sun comes out", "when the sun comes out, I'll go with my sister to the market. There are many things I like on the market, so my sister is busy." In "New Bashan", "Bashan is red and beautiful, Bashan people like to smile, Bashan is red and gorgeous, happy life is endless." People express their desire for love and praise for a happy life through singing.

\section{INHERITANCE AND PROTECTION}

\section{A. Implementing the laws on intangible cultural heritage and clarifying the main responsibility}

With the development of global economy and culture, the state pays more and more attention to the field of culture. In 2005, the State Council proposed the protection of intangible cultural heritage for the first time, and promulgated "laws of the People's Republic of China on the intangible cultural heritage" on February 25, 2011, which came into force on June 1 , 2011. At the same time, the first batch, second batch, third batch and fourth batch of national intangible cultural heritage lists were approved on June 1, 2011, June 14, 2008, June 10, 2011 and July 16, 2014. The State Council also decided that the second Saturday in June will be China's "Cultural Heritage Day" from 2006. On November 6, 2013, China Intangible Cultural Heritage Protection Association, which is subordinate to the Ministry of culture, was also established. Also, the State Council issued the "notice on strengthening the protection of cultural heritage", and formulated a four-level protection system of "state + province + city + county", requiring all localities and relevant departments to implement the working principle of "protection first, rescue first, rational utilization, inheritance and development", and earnestly do a good job in the protection, management and rational utilization of intangible cultural heritage.

In order to implement the national laws and regulations, it is necessary to make clear the main responsibility, keep close contact with each other, and cooperate with each other. It is better to avoid the chaos of being nobody's business, mutual prevarication, and multi management, resulting in a waste of human resources. According to the spirit of the documents of the State Council and the Department of Culture, the municipal government should further implement the management, protection, inheritance and application system of material and culture of intangible cultural heritage on the basis of the previous "Dazhou intangible cultural heritage protection regulations". The Bureau of culture and broadcasting is responsible for the specific 
implementation of each unit, each department or even post, and the cultural center and intangible cultural heritage protection association implement the system with the assistance of other units. The specific work of intangible cultural heritage culture should be carried out in accordance with the unified deployment of provinces and cities.

In the inheritance and protection of Madu folk songs, some specific matters should be implemented. It is better to have clear requirements for the protection, inheritance, utilization and development of Madu folk songs, so as to form a three-dimensional work situation in which the upper and lower links are cooperated.

\section{B. Training relevant personnel and strengthening publicity}

Another important measure to inherit and protect intangible cultural heritage is to train relevant personnel and strengthen publicity. Intangible cultural heritage has profound historical accumulation, strong professionalism and limitations. If people do not understand, do not differentiate, or even act recklessly, it will not only fail to do a good job, but will do a seemingly clever thing which turns out to be a foolish one instead. Madu folk songs have the characteristics of large quantity, pure lyrics, beautiful melody, long history, sufficient charm and deep thought. In order to make people understand it, appreciate it and love it, it is better to train the relevant personnel of government departments, cultural departments, education departments and various associations to deeply understand the cultural heritage, historical imprint, characteristics of words and music, ideological connotation and current difficulties of Madu folk song. Combined with the current situation, it analyzes the future development and inheritance protection path.

Then, it is necessary to further strengthen publicity, from the government to the public, from the countryside to the city, from schools to enterprises. It can make the publicity by means of TV stations, station music, square music, mobile phone ringtones, QQ, WeChat, Weibo, radio, road advertising, clothing advertising, food advertising. The multi-dimensional publicity will make people go deep into the Madu folk songs, so as to play the sense of ownership.

\section{Strengthening exchanges and cooperation and expanding international vision}

It is difficult for a single tree to make a forest, and a lone goose cannot fly far away. Only by further strengthening exchanges and cooperation can people better inherit and protect Madu folk songs. Madu folk song is not only the expression of art, but also the presentation of literature; it is not only the expression of music, but also the display of dance. Its multiple forms provide a good foundation for communication and cooperation. When adding fine arts in Madu folk song, costume design will increase the artistry and appreciation of performance; if it is integrated into film and television, it will further enhance the audio-visual effect; if it is added into literary works, it will also have more artistic conception. In addition to academic integration with fine arts, literature and drama, people can also carry out exchanges and cooperation with foreign countries. It also held the exchange meeting, forum and research meeting of Madu folk songs.

With the rapid development of global cultural diversity, Dazhou should also speed up its pace, keep pace with the pace of the times, take full advantage of various platforms to expand international vision, so that foreigners can understand and like Madu folk songs. The "Chang'e-1" lunar exploration satellite, launched in October 2007, was accompanied by "Kangding Love Song", the Madu folk song, providing a foundation for increasing exchanges. With the help of the foreign enterprise office and foreign publicity office of municipal government, the foreign teachers, foreign students and foreign lectures of the college of arts and science (vocational and technical college) are introduced and exchanged, so as to expand the horizontal exchange.

\section{Increasing the support and the reward}

In the inheritance and protection of intangible cultural heritage, it is necessary to increase the support and the reward. According to the actual situation, the government should implement appropriate preferential policies for the inheritors of Madu folk songs, care and help them in life, work and ideology, solve their practical difficulties, cherish and protect these inheritors of intangible cultural heritag. Then, they can inherit the cultural heritage of Madu folk song well

Increasing the reward amount can effectively make the protectors feel the government's attention and care, and can also make them concentrate on the interpretation of works. Second, it can encourage more people to participate in the inheritance and protection of intangible cultural heritage, and obtain a sense of dignity, existence and achievement with the master role. Third, increasing the reward amount can provide favorable conditions for the further development and innovation of Madu folk songs, and create more sufficient space and form an optimization mechanism, so as to constantly deepen and tap intangible cultural heritage.

\section{E. Entering classroom teaching and promoting multi- dimensional competition}

Entering the classroom teaching and promoting multi-dimensional competition is another important way to inherit and protect Madu folk songs. First of all, Madu folk songs should be incorporated into the local 
music teaching materials, especially the representative songs should be set as compulsory songs. Music teachers should master them, and students understand and learn them. These songs can go deep into the hearts of teachers and students through the classroom teaching, so as to spread widely. Secondly, on the basis of the established association of Madu folk songs, it is necessary to further expand the team, establish the Madu folk song performance group and the Madu folk song inheritance group, and implement the specific tasks and related matters, so that they can really operate and play a team role. The third is to hold the Madu folk song competition. Through the competition, people will actively participate in. At the same time, outstanding singers of Madu folk songs will be selected for recording and video production, and awards will be given. Finally, a special creative team should be established to continuously innovate and develop Madu folk songs. On the basis of maintaining its original characteristics, modern techniques and singing methods should be integrated to improve its composition, clothing, accompaniment and performance, so as to better inherit and protect Madu folk songs.

\section{CONCLUSION}

Madu folk song is not only the combination of traditional art and modern art, but also the representative of the fusion of northern and southern tones. It is not only the organic integration of intangible cultural heritage culture and red culture, but also the typical carrier of revolutionary spirit and red spirit. Its profound cultural connotation and historical accumulation not only provide important elements for people to study people's life, work, singing and dancing in Sichuan Province, but also provide huge space for the industrial culture, image culture and economic culture of Bashan. To study the inheritance and protection of Madu folk songs is not only to meet the social needs but also the cultural needs, which is more in line with the call of the times of the national renaissance.

\section{References}

[1] Intangible cultural heritage [EB/OL] people.com.cn. https://baike.so.com/doc/2019/09/4/227948-241114.html

[2] Intangible cultural heritage [EB/OL]. Guangdong Culture Network. https://baike.so.com/doc/2019/09/4/227948241114.html

[3] Law of the People's Republic of China on Intangible Heritage [Z]. 2011-02-25

[4] Dazhou City held the Intangible Cultural List Exhibition [EB/OL]. Sichuan News http://local.newssc.org/system/2019/09/4/001376758.htm

[5] The National Intangible Cultural Heritage "Sanhui Color Pavilion" re-emerges [EB/OL]. China Economic Herald, http://www.ceh.com.cn/shpd/2019/09/4/359784.shtml .
[6] Zhao Ying. He Yuanping. Research on Baqu Folk Song Culture [M]. Henan: Henan People's Publishing House, 2011-8-1. (in Chinese)

[7] Liu Gaoyang. Exploration of the red elements of Bashan folk songs and the value utilization. Sichuan Drama, 2019 (07): 126129. (in Chinese) 